\title{
As principais evoluções dos comportamentos alimentares: o caso da França
}

\author{
Main evolutions in human food practices: \\ French example
}

Jean Louis LAMBERT ${ }^{1}$

Mário Otávio BATALHA²

Renato Luiz SPROESSER ${ }^{3}$

Andréa Lago da SILVA ${ }^{2}$

Thelma LUCCHESE ${ }^{4}$

\section{RE S U M O}

Durante a segunda metade do século XX, o desenvolvimento econômico e as evoluções dos modos de vida ocasionaram modificações importantes nos comportamentos alimentares. Tais evoluções foram particularmente analisadas para o caso da França. Confrontadas a um contexto de abundância, as populações adotaram uma conduta alimentar mais energética. Tal conduta resume-se, sobretudo, em um alto consumo de produtos de origem animal. Porém, entre grupos de indivíduos ricos e após um período de saturação, a atração pelo consumo desmedido tal produto, tornou-se menos intensiva. Novas preocupações orientadas à saúde e às formas de mantê-la em bom estado foram despertadas. O aumento do número de mulheres salariadas e o desenvolvimento das atividades de lazer alteraram a gestão do tempo empregado à alimentação. Na busca pelo ganho de tempo, os consumidores passaram a procurar por alimentos prontos para serem consumidos e a realizarem suas refeições fora do domicílio. As culturas alimentares não evoluem tão rapidamente como as transformações ocorridas em todo o sistema de oferta alimentar, com isso afirma-se que a industrialização, a internacionalização e as inovações de toda a cadeia agroalimentar geram ansiedades no consumidor. Todas essas transformações e tendências, que são observadas em países ricos, podem ser percebidas quando os comportamentos alimentares de populações ricas de países em desenvolvimento são analisados.

Termos de indexação: conduta na alimentação, consumo de alimentos, disfusão de inovações, gestão do tempo, preferências alimentares, França.

\footnotetext{
1 École Nationale d'Ingénieurs des Techniques des Industries Agricoles et Alimentaires. Rue de la Geraudiere BP 82225 CP 44322 . Nantes, France.E-mail:<lambert@enitiaa-nantes.fr>

2 Departamento de Engenharia de Produção, Universidade Federal de São Carlos. Rod. Washington Luís, km 235, 13565-905, São Carlos, SP, Brasil. Correspondência para/Correspondence to: M.O. BATALHA. E-mail: <dmob@dep.ufscar.br>, <deialago@dep.ufscar.br>.

3 Departamento de Administração, Economia e Direito, Universidade Federal de Mato Grosso do Sul. Campo Grande, MS, Brasil.E-mail:<drls@nin.ufms.br>.

4 Doutoranda em co-tutela, Universidade Federal de São Carlos. São Carlos, SP, Brasil, e École Nationale d'Ingénieurs des Techniques des Industries Agricoles et Alimentaires. Nantes, France. E-mail: <thelma.lucchese@gmail.com>.
} 


\section{A B S T R A C T}

Important modifications in consumer food habits were caused by both economic development and evolutions in life style during the second part of the XX century. These evolutions were analyzed, in particular, in the case of France. Easy accessibility to food (abundance context) led the populations to adopt high caloric food intakes, such conduct resulting, above all, in an elevated consumption of products of animal origin. However, after a period of saturation, the unlimited attraction to the consumption of such products became less intense amongst the richer, more privileged social groups. New, health oriented concerns, and ways to maintain good health became important. The rise in the number of women earning salaries and the development of leisure activities altered the management of time with respect to feeding. Aiming at gaining time, the consumers concentrated more on ready-to-eat foods and eating out of the home. However the food cultures failed to evolve as quickly as the transformations occurring in the food marketing system, and thus it can be affirmed that industrialization, internationalization and innovations throughout the whole agro-food chain led to consumer anxiety. All such transformations and tendencies observed in the rich countries can also be perceived in the food habits of rich populations in developing countries.

Indexing terms: feeding behavior, food consuption, diffusion of innovation, time organization, food preferences, French.

\section{N T R O D U ÇÃ O}

A evolução do comportamento alimentar sempre esteve fortemente ligada às vicissitudes da longa história da humanidade. Os trabalhos de historiadores, como Flandrin \& Montanari', explicitam claramente estas relações. No entanto, a evolução dos hábitos alimentares é muito mais lenta que a de outros hábitos correntes da vida cotidiana. É fato que as pessoas trocam mais facilmente de carro ou de sapatos do que de receitas culinárias ou de práticas alimentares.

Grande parte da humanidade experimentou, ao longo da segunda metade do século $X X$, melhorias consideráveis na sua condição de vida e na sua renda. Não obstante, já ao final do século XIX², alguns estatísticos observaram que as despesas com o consumo alimentar não eram proporcionais a este aumento da renda ${ }^{(5)}$. Assim, descobriu-se que, ainda na atualidade, as despesas alimentares possuem limites definidos e que a parte do orçamento familiar destinada à alimentação diminui com o aumento de renda.

Em 1960, por exemplo, os franceses destinavam, em média, 30\% da sua renda para a alimentação. Atualmente esta porcentagem é de aproximadamente $20 \%$, sendo $15 \%$ para o consumo no domicílio e $5 \%$ para o consumo fora do domicílio.

Por outro lado, observou-se nos últimos anos, não só na França, mas em várias regiões do planeta, um crescimento de produção e produtividade em todos os elos das principais cadeias agroindustriais produtoras de alimentos: agricultura, pesca, indústria, food services, distribuição etc. O progresso dos meios de transporte, aliado às modificações geopolíticas mundiais, têm acelerado o livre comércio de mercadorias, entre as quais destacam-se os alimentos.

Estas condições levaram a um crescimento extremamente rápido da disponibilidade alimentar nos países mais ricos. Além disso, os ganhos de produtividade e as importações de países mais pobres resultaram na diminuição dos preços relativos dos alimentos naqueles países.

Durante a segunda metade do século XX, ao mesmo tempo em que a disponibilidade alimentar cresceu, as necessidades nutricionais diminuíram. Neste mesmo espaço de tempo, a população dos países ricos tornou-se cada vez mais sedentária. As modificações na organização do trabalho (mecanização, automatização,

\footnotetext{
5 Destacam-se, nesta direção, os trabalhos e leis de Engel citados por McIntosh².
} 
robotização etc), o desenvolvimento de meios de transporte e o aumento das facilidades domésticas, levaram a uma redução substancial das atividades físicas. Assim, em algumas décadas, o nível individual médio de gastos energéticos reduziu-se de $25 \%$ a $30 \%$, passando de 3000-4000kcal a 2000-3000kcal/dia. Convém lembrar que o crescente peso demográfico de pessoas da chamada melhor idade vai reduzir ainda mais a necessidade quantitativa de energia a ser ingerida pela população.

Assim, considerando-se a trajetória da história da humanidade, estas mudanças podem ser vistas como uma verdadeira revolução nas condições de oferta e demanda de alimentos às populações.

\section{A abundância alimentar: um contexto completamente novo}

O contexto dominante ao longo da história da humanidade sempre foi o de escassez alimentar. A principal preocupação das populações era a de possuir alimentos em quantidade suficiente para a sua sobrevivência em condições adequadas. Nesta situação, segurança alimentar significava possuir um estoque de alimentos suficiente para garantir a sobrevivência. Tal situação ainda pode ser encontrada em várias nações. A Food and Agriculture Organization (FAO) estima que cerca de 800 milhões de pessoas, em todo o mundo, sofrem de problemas de subnutrição ${ }^{3}$.

No entanto, as camadas mais ricas da população (classes mais abastadas de países pobres e a maior parte dos indivíduos dos países ricos) encontram-se atualmente em um contexto de consumo alimentar completamente novo: pletora alimentar. Se em um contexto de escassez as restrições econômicas são os elementos determinantes das escolhas alimentares, em um contexto de abundância e riqueza estas restrições tornam-se secundárias. Neste último caso, os consumidores podem escolher sua alimentação em função de fatores culturais, sociais e psicológicos.

Esta camada mais rica da população do planeta confronta-se agora com a abundância alimentar, uma situação jamais observada pela espécie humana ${ }^{4}$. Como a humanidade sempre viveu em um contexto de escassez alimentar, o sentimento primário de sobrevivência sempre a atraiu para o consumo de alimentos e nutrientes mais energéticos, justificando, dessa forma, uma preferência por sabores açucarados e por lipídios. Assim, quando esta mesma população depara-se com uma quantidade de alimentos que ultrapassa o que normalmente suas necessidades exigem, ela tende a fazer reservas em tecido adiposo, pois poderá utilizá-las em caso de um retorno do período de escassez alimentar. Dessa forma, esse novo contexto de abundância alimentar conduz a uma atitude paradoxal: "ficar magro" em um longo período de "vacas gordas" (Figura 1).

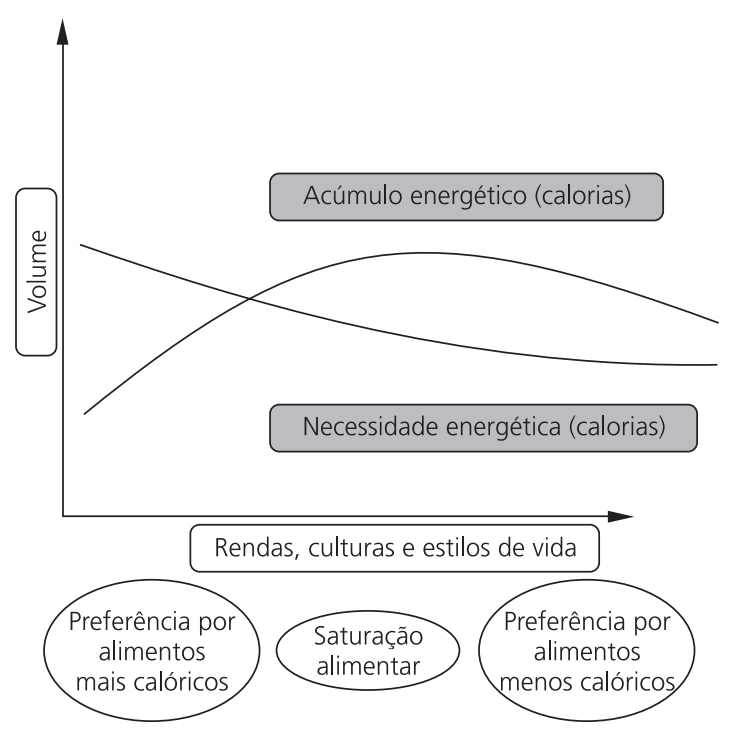

Figura 1. O paradoxo da abundância: "ficar magro" em Fonte: Lambert ${ }^{5}$ período de "vacas gordas".

Um dos resultados desta situação é que a fração da população dos países mais pobres que consegue ultrapassar a linha da pobreza começa 
a enfrentar graves problemas de obesidade. Uma outra parte da população, após a conscientização desta situação de saturação alimentar, parece ter começado um processo de reajuste nas suas dietas alimentares. Os mais ricos, apoiados pelo avanço científico e pela opinião de especialistas (notadamente de nutricionistas), têm procurado desenvolver um modelo alimentar ideal, que se resume em comer menos para viver melhor e viver mais tempo sem envelhecer. No entanto, não existem dúvidas que serão necessárias várias gerações para a difusão de um modelo adaptado a esse novo contexto resultando, talvez, em uma diminuição das frações da população com problemas de obesidade.

\section{A substituição do consumo de produtos animais e vegetais segundo o nível de desenvolvimento econômico}

Os indivíduos, enquanto consumidores de alimentos, distinguem várias categorias do que é consumido em seus ambientes: os reinos animal e vegetal, que eles consideram parcialmente como comestíveis, e o reino mineral que, com algumas exceções, como o sal e a água, é considerado como não comestível. Assim, o "cardápio alimentar" é constituído de proporções variáveis de produtos de origem animal e vegetal.

Como as carnes proporcionam sensações de saciedade fortes e duradouras devido, entre outros motivos, à dificuldade de assimilação de moléculas complexas de aminoácidos, elas são, via de regra, preferidas, quando comparadas a produtos vegetais, por todas as populações que buscam a saciedade alimentar (Figura 2).

Como a produção de carnes é relativamente mais cara (devido à transformação de proteínas vegetais em proteínas animais), a necessidade de consumo destes produtos só pode ser satisfeita quando o nível de renda permite ${ }^{6}$.

Desta forma, existe uma relação muito forte entre o desenvolvimento econômico e o consumo de proteínas de origem animal ${ }^{6,7}$.
Há cerca de 25 anos as camadas mais ricas da população começaram a tomar consciência que elas comiam mais do que precisavam. Neste momento, estes indivíduos começaram a procurar tanto por alimentos que proporcionassem uma sensação mais intensa de saciedade como por alimentos mais leves, de digestão mais rápida. Este fato explica, em parte, o grande aumento da produção e de consumo de produtos light e diet no final dos anos 80 . Os problemas dos excessos no consumo de alimentos estão na origem das mudanças nas preferências alimentares observadas nos países ocidentais ao longo da década de $80^{8,9}$. Convém relembrar que estas mudanças foram mais pronunciadas nos extratos mais ricos da população de todos estes países ${ }^{7,10}$. Neste momento, a atração pelos efeitos de saciedade alimentar produzido pelas carnes começa a diminuir sensivelmente (Figura 3).

Comparando-se as Figuras 4 e 5, pode-se perceber o início da inversão e tendência de substituições entre os alimentos. Os produtos de origem vegetal têm um novo atrativo, o qual é reforçado pela mudança no discurso dos nutricionistas. No caso da França, as referências recorrentes à denominada dieta mediterrânea e o lançamento do Plano Nacional de Nutrição-Saúde têm preconizado a necessidade de

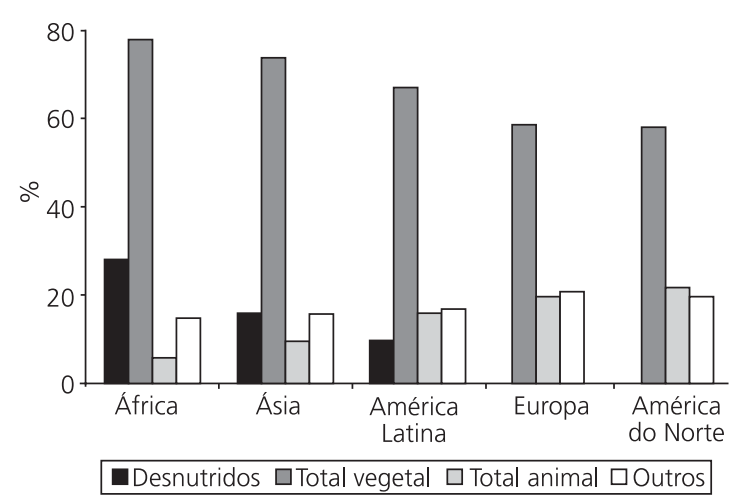

Figura 2. Contribuição, em porcentagem, aos ganhos energéticos quanto ao consumo de produtos de origem vegetal e animal e a porcentagens de desnutridos nos continentes mencionados.

Fonte: Food and Agriculture Organization ${ }^{11}$. 
aumentar o consumo de frutas, verduras e legumes $^{13}$. As Figuras 4 e 5 apresentam uma análise do consumo francês de produtos alimentares, demonstrando a involução quanto aos produtos de origem animal e a evolução do consumo francês de produtos de origem vegetal.

Assim, o consumo do conjunto de vegetais (cereais, legumes, verduras e frutas), que diminuía em favor dos produtos de origem animal (carnes e embutidos), aumentou após vinte anos. Este tipo de aumento de consumo aconteceu, sobretudo, nas frações mais ricas das populações francesa e mundial.

\section{Neo-vegetarianismo e novos comporta- mentos relacionados ao consumo de produtos de origem animal}

Em um contexto de abundância alimentar, as carnes vermelhas, cuja imagem simbolizava a vivacidade e a força física (o cavalo, por exemplo), perdem seu caráter atrativo em favor dos produtos lácteos e das carnes brancas, principalmente dos pescados. Estes alimentos, até pouco tempo atrás, eram considerados como menos interessantes, pois proporcionavam um sentimento de saciedade menor do que aquele das carnes vermelhas. Tal fato ainda pode ser constatado pela observação

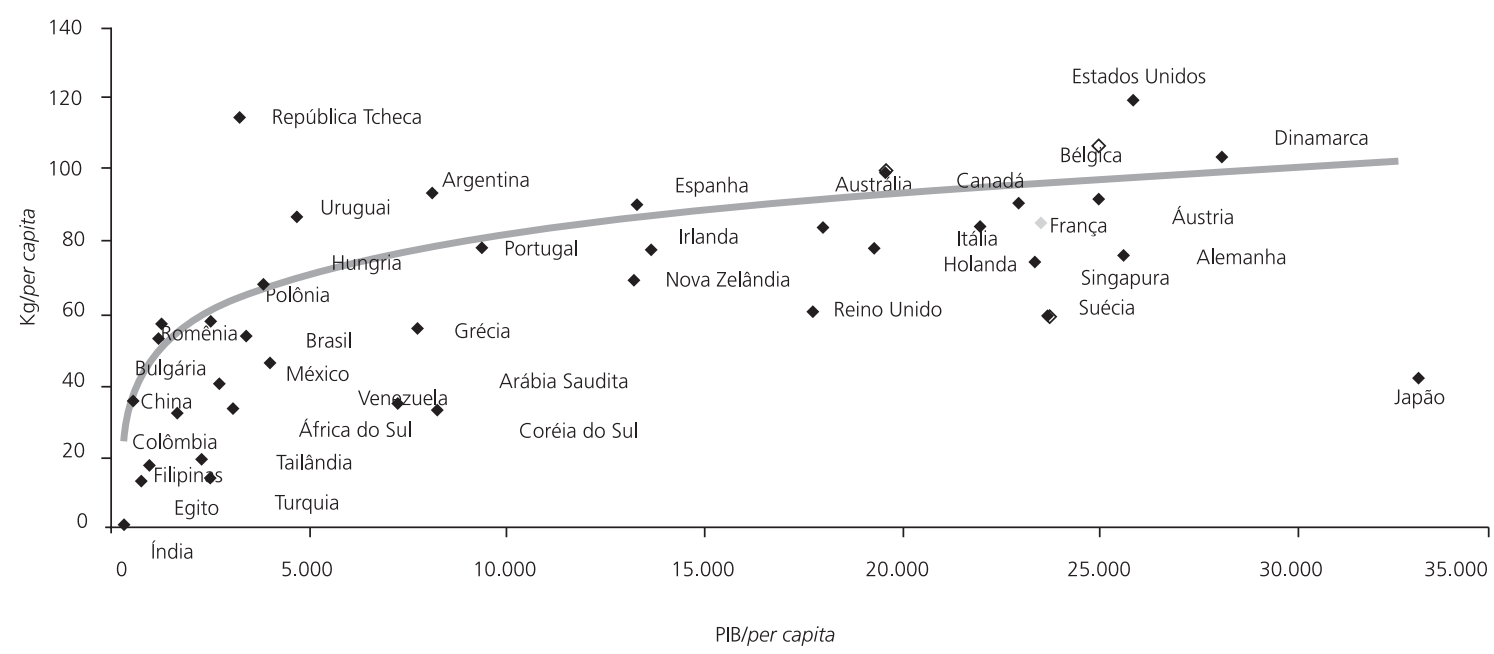

Figura 3. Consumo de carne das nações e sua relação com a renda. Fonte: Rabobank International ${ }^{12}$.

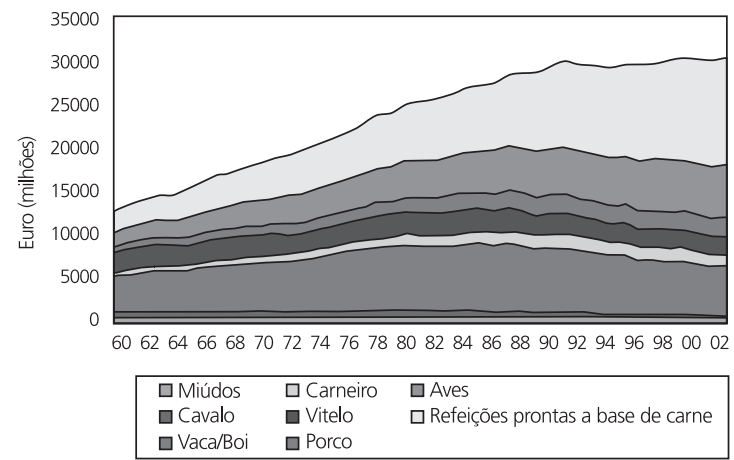

Figura 4. Consumo francês, segundo renda do domicílio, de produtos de origem animal.

Fonte: INSEE ${ }^{14}$, citado por Lambert ${ }^{15}$.

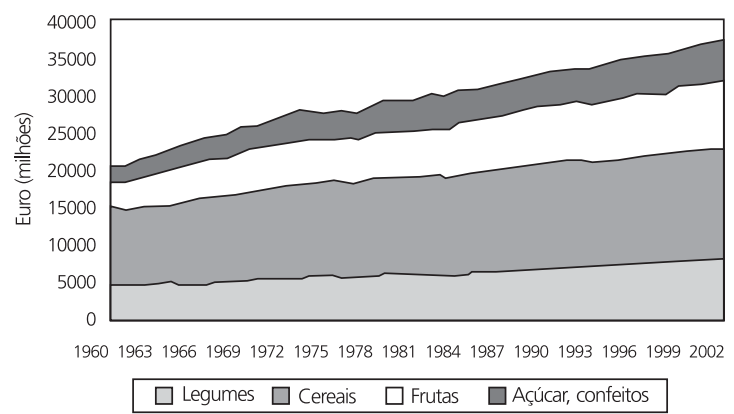

Figura 5. Consumo francês, segundo renda do domicílio, de produtos de origem vegetal.

Fonte: INSEE ${ }^{14}$, citado por Lambert ${ }^{15}$. 
da evolução da repartição do consumo dos produtos de origem animal e produtos lácteos nos domicílios franceses (Figura 6).

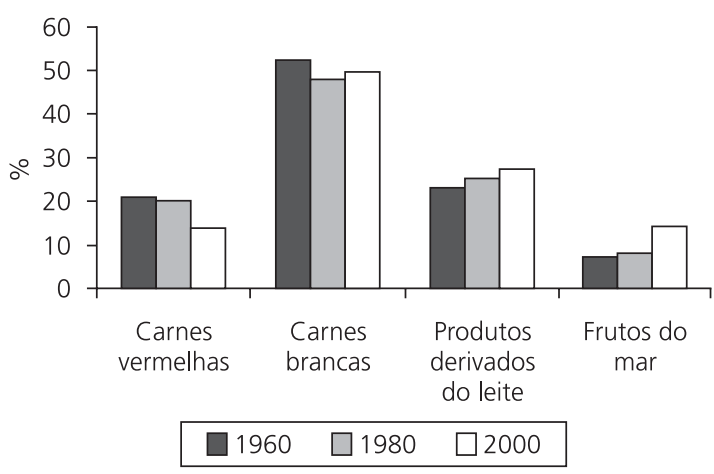

Figura 6. Evolução, em porcentagem, do consumo de produtos de origem animal nos domicílios franceses. Fonte: INSEE ${ }^{14}$, citado por Lambert ${ }^{15}$.

Não caracterizando um puro vegetarianismo (regime alimentar baseado unicamente na utilização de vegetais), o consumo de produtos de origem vegetal e de produtos de origem animal, sobretudo o de carnes brancas, pode ser considerado como uma combinação alimentar que caracteriza um tipo de néo-vegetarianismo. Esse novo comportamento de consumo é explicado pelo atual contexto de superabundância alimentar, ou seja, os indivíduos deixam de se preocupar tanto com a falta de alimentos quanto com a condição de saciedade promovida pelos mesmos.

Vialles ${ }^{16}$ verificou duas atitudes principais dos indivíduos em relação ao consumo de carne animal. A primeira atitude descrita pelo autor é a dos indivíduos chamados de zoofágicos. Consumidores que assumem tal atitude alimentam-se de carnes animais sem serem incomodados pelo reconhecimento do animal no alimento consumido. Por outro lado, a atitude de indivíduos chamados pelo autor de sarcofágicos revela um extremo incômodo desses quanto ao reconhecimento do animal nos produtos consumidos. Um exemplo do comportamento de consumidores sarcofágicos seria a rejeição quanto ao consumo de carnes vermelhas, pois são estigmatizadas pela sua cor, que lembra o sangue e o próprio animal.

Fischler ${ }^{17}$ explica que existe a necessidade de uma certa descontinuidade e distância entre o homem e o animal, para que o consumo de carnes seja aceito. A zoofagia é praticada por consumidores que têm uma concepção clara da superioridade humana e percebem, ainda, uma descontinuidade, ou seja, uma ruptura precisa e identificada entre o homem e o animal. Por outro lado, a sarcofagia é, de fato, a negação da imagem do animal no alimento que será consumido. Os caçadores e criadores de animais são, de modo geral, mais zoofágicos que os agricultores. Entretanto, esses últimos têm a consciência de sua superioridade vis-à-vis dos animais de tração, dos quais eles aceitam comer a carne. Em contrapartida, em todos os casos, os animais domésticos, muito próximos e considerados como amigos do homem, não são classificados como comestíveis. Assim, logo que um animal muda de status, como é caso do cavalo na França, já há algumas décadas, e recentemente o do coelho, ele é progressivamente excluído das opções alimentares.

A urbanização crescente pode ser apontada como um dos principais fatores que distancia os indivíduos do universo animal. Com isso, quando o homem introduz em seu habitat animais de companhia, a condição de alimento potencial do último é completamente abandonada, uma vez que o animal é visto como um amigo 9,17.

Cabe, então, lembrar que, em países que atravessam períodos iniciais de desenvolvimento econômico, a substituição de produtos de origem vegetal por produtos de origem animal é uma ação típica realizada pelos indivíduos dessas nações. Porém, quando os alimentos tornam-se abundantes e ocorre uma saturação alimentar, uma substituição inversa passa a ser percebida (produtos animais são substituídos por vegetais), conforme ilustrado na Figura 7. A Figura 8 apresenta tal evolução considerando o caso da França quando expõe a evolução do consumo, 


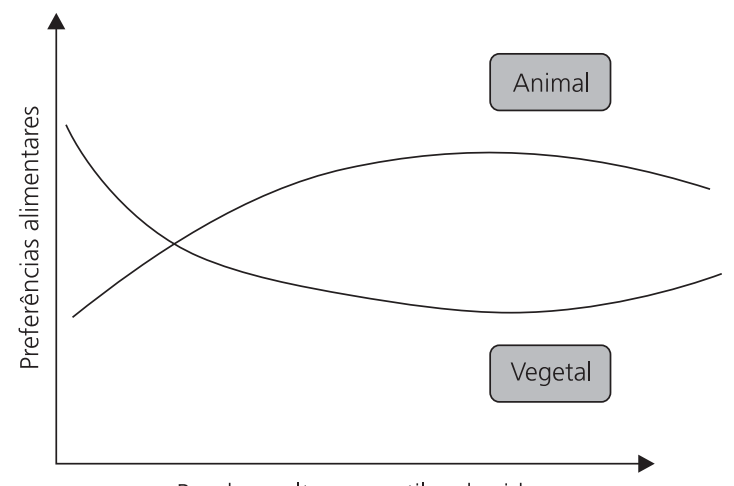

Rendas, culturas e estilos de vida

Figura 7. Tendência mundial, segundo evolução dos níveis de vida, do consumo de produtos de origem animal e vegetal.

Fonte: Lambert ${ }^{5}$.

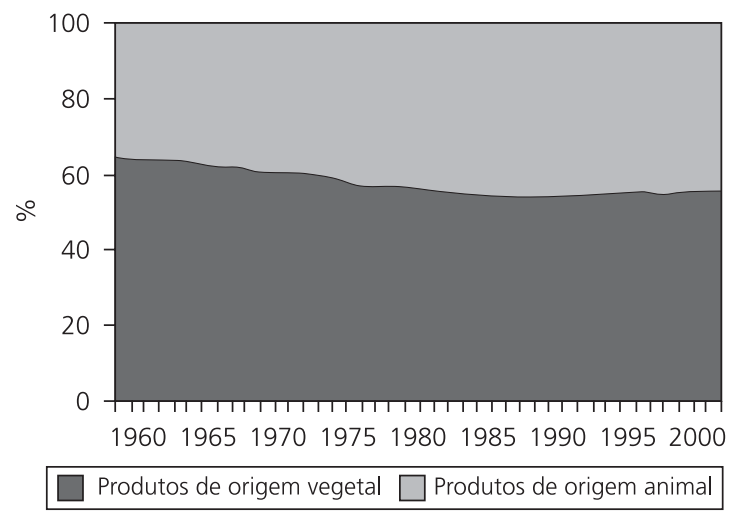

Figura 8. Evolução das despesas dos domicílios franceses, em porcentagem de gastos, relacionadas ao consumo de produtos de origem animal e vegetal.

Fonte: INSEE ${ }^{14}$, citado por Lambert ${ }^{15}$.

realizado em domicílio, de produtos de origem animal e vegetal ao longo de quarenta anos. A análise dessa figura permite a constatação do retorno à preferência por produtos de origem vegetal por parte dos franceses.

\section{Alimentação e gestão do corpo(6)}

A evolução da medicina permitiu um importante aumento da expectativa de vida dos indivíduos. Mas, paradoxalmente e, sem dúvida, em associação ao peso demográfico da população idosa, as preocupações relacionadas à saúde tornaram-se mais evidentes e a própria noção de saúde modificou-se.

A boa saúde que era associada à noção da ausência de doenças está, cada vez mais, relacionada ao bem-estar, ao aumento da expectativa de vida e à redução das consequências do processo de envelhecimento. A gestão do corpo e da saúde, que assumia um caráter essencialmente curativo, tornou-se igualmente preventiva a médio e longo prazos. Nesse sentido, inquietações habituais quanto à qualidade digestiva dos alimentos são complementadas por preocupações quanto ao efeito, em longo prazo, de substâncias nocivas dos mesmos para a saúde humana. A diminuição do consumo de certos alimentos - que poderiam estar ligados ao aparecimento de determinados tipos de câncer - $\mathrm{e}$ a ocorrência de uma queda brusca do consumo de carne bovina - devido aos casos da doença da vaca louca - são exemplos da evolução dessas preocupações. Além disso, poder-se-ia destacar que, devido a essas novas preocupações, uma atenuação da fronteira entre alimentos $e$ medicamentos vem sendo percebida.

Porém, cabe destacar que, quanto mais fortes forem as restrições econômicas para um determinado grupo populacional, mais a gordura será interpretada como símbolo de festa, sobrevivência, riqueza e de distinção. Assim, em sociedades ocidentais ricas, quando o nível de vida permite às classes médias maior facilidade de acesso a alimentos ricos em gordura, a corpulência pode passar a ser interpretada como obesidade. Como consequência, a gordura torna-se símbolo de pobreza e as classes ricas desenvolvem um modelo de corpo magro, o qual passa a ser um objetivo e símbolo de sucesso social.

Considerando a abordagem dos profissionais da saúde que trabalham com nutrição,

\footnotetext{
${ }^{6}$ A expressão alimentção e gestão do corpo é empregada neste texto para explicar os cuidados e preocupações dos indivíduos quanto à relação causa-efeito da alimentação em seu corpo.
} 
a relação entre a alimentação e a saúde é bastante enfatizada. Face à constatação de comportamentos alimentares excessivos, praticados principalmente por populações ricas (com destaque para indivíduos norte-americanos), preocupações dietéticas, noções de higiene de vida e equilíbrio alimentar foram desenvolvidas. Entretanto, os discursos dos nutricionistas revelaram-se pouco eficazes na difusão das práticas de comportamentos alimentares equilibrados. Tal afirmação pôde ser comprovada por estudos que constataram que grande parte dos indivíduos associava comportamento alimentar equilibrado ao aumento do consumo de produtos com composição nutricional alterada (menor quantidade de lipídeos ou glicídios, por exemplo) e à redução do consumo de alimentos com composição nutricional reforçada (alimentos enriquecidos em cálcio ou ferro, por exemplo). O modismo do consumo de produtos light e diet e, posteriormente, o aparecimento e a popularidade de produtos considerados como substitutos de refeições impulsionaram o desenvolvimento de um número crescente de indústrias alimentares dedicadas à produção de complementos alimentares e alimentos nutracêuticos (alimentos funcionais). Esse conjunto abrange, atualmente, um universo de produtos que flutua entre os alimentos e os medicamentos. Vale ressaltar que até a década de 80 , sobretudo em países latinos, essas categorias de produtos possuíam características absolutamente distintas.

Preocupações estéticas e dietéticas, as quais são chamadas por este trabalho de preocupações diestéticas, caracterizam o modelo de corpo magro referido anteriormente e que se propaga, particularmente, entre mulheres de países latinos. Regimes de emagrecimento se desenvolvem e alimentos com funções cosméticas aparecem. Tais regimes podem ser associados, pelos mais abastados, com cirurgias estéticas (caso particularmente importante no Brasil).

A saúde e o prazer são importantes determinantes das escolhas e práticas alimentares dos povos. De modo geral, em culturas puritanas anglo-saxônicas o conceito de saúde é um forte determinante de tais práticas. A expressão comer para viver é empregada para descrever os hábitos dessas culturas. Já em culturas latinas epicuristas (aquelas que buscam, entre outros, os prazeres gastronômicos) o prazer determina as escolhas alimentares. Dessa forma, a expressão viver para comer caracteriza melhor os hábitos dessas culturas. Porém, constata-se que esses dois determinantes vêm se misturando em confrontações culturais mundiais, principalmente, devido às preocupações sanitárias voltadas à alimentação dos indivíduos. Na França, por exemplo, tais preocupações deram origem à formulação de políticas alimentares que vêm mudando ao longo do tempo. As políticas da década de cinqüenta, priorizavam, sobretudo, a segurança alimentar, tendo como principal objetivo a garantia do abastecimento alimentar da população. No final do século XX, preocupações quanto à segurança sanitária dos alimentos passaram a ser tema central dessas políticas. A preocupação relacionada ao aumento dos casos de obesidade, entre outros temas que provocam inquietude dos profissionais ligados à saúde humana, promoveu, na França, a criação da Agência Francesa de Segurança Sanitária dos Alimentos (AFSSA), em 1999, e do Programa Nacional de Nutrição e Saúde (PNNS), em 2002.

Entretanto, considerando o vocabulário empregado para definir o termo - segurança sanitária dos produtos alimentares - torna-se necessário notar que os consumidores reivindicam que os alimentos possam garantir-lhes saúde segundo diferentes representações. Dessa forma, para os mais preocupados quanto a doenças relacionadas a uma má conduta alimentar, os produtos consumidos devem garantir a ausência de substâncias patogênicas e tóxicas em sua composição. Quando preocupações estéticas são consideradas, a quantidade energética e o equilíbrio nutricional do que é consumido, apresentam-se como pensamentos dominantes nesse vocabulário. Por fim, levando em conta as preocupações de populações ricas e envelhecidas 
- aquelas buscam viver mais tempo e conservando ao máximo sua juventude - os alimentos demandados deverão contribuir para tal objetivo, por exemplo, oferecendo em sua composição substâncias antioxidantes.

\section{Gestão do tempo e preferência por produtos prontos para serem consumidos}

A evolução dos modos de vida e a importância dada às atividades de lazer fazem surgir novas demandas de consumo, sendo essas tendências melhor percebidas no caso de populações ricas. Além disso, o melhoramento do nível de vida e a importância do papel social das mulheres despertaram o interesse dessas populações por uma nova gestão do seu tempo.

Para se alimentar é preciso dispor de recursos financeiros e de tempo, uma vez que grande parte dos produtos alimentares vendidos não pode ser consumida imediatamente. Consumidores se encarregam da finalização da produção dos alimentos semiprontos, da mesma forma como confeccionavam suas vestimentas antes do desenvolvimento do prêt à porter (pronto para utilizar). Considerando uma produção alimentar doméstica, faz-se necessária a aquisição de alguns equipamentos, o domínio de certos conceitos culinários e a disposição de tempo que será consagrada durante o preparo dos alimentos ou refeições.

São, ainda, as mulheres que se responsabilizam por $80 \%$ das atividades alimentares domésticas. Porém, sobretudo nas sociedades ocidentais, elas procuram progressivamente se liberar desses tipos de atividades. Essas mesmas mulheres investem em formação e informação, procurando desempenhar atividades profissionais que as valorizem socialmente e assegurem sua autonomia financeira. A necessidade por tal autonomia cresce na medida em que o número de divórcios e o número de mulheres celibatárias aumentam. A transmissão de conhecimentos culinários entre gerações acontece em menor intensidade, enquanto aumenta a ocorrência de relatos de jovens quanto à falta de conhecimentos culinários. O modelo cultural da dona de casa ou da administradora do lar passa a ser menos evidente nas classes média e rica. Um modelo de igualdade dos sexos começa a ser mais imperativo. Considerando que a realização de atividades domésticas é uma ação pouco reconhecida, o descontentamento de mulheres dessas classes, que até agora desempenham essas atividades, pode ser percebido em seus discursos.

Ainda é preciso considerar que, principalmente em sociedades ricas, as atividades de lazer se desenvolvem e acabam concorrendo com outras atividades, principalmente as domésticas. Com o aumento do nível de vida, a restrição de tempo torna-se um fator determinante nas opções dos consumidores. Independentemente da classe social, todos os indivíduos dispõem de vinte e quatro horas por dia. Entretanto, consumidores de classes menos favorecidas afirmam compensar os baixos salários realizando atividades domésticas (jardinagem, pequenos consertos, atividades culinárias, entre outras), o que aumenta seu tempo de trabalho e diminui seu tempo de lazer. Por outro lado, consumidores de classes mais abastadas contratam terceiros para a realização das tarefas domésticas. No Brasil, os baixos salários pagos aos empregados domésticos permitem que indivíduos da classe rica e muitos indivíduos das classes médias contem com esses serviços. Em outros países ocidentais, cuja mão-de-obra terceirizada é melhor remunerada, a compra de produtos com serviços associados é muito praticada por classes sociais mais ricas. Quando o nível de vida permite a uma camada crescente da população satisfazer suas necessidades elementares como alimentação, será o tempo consagrado às atividades de lazer que se tornará um símbolo de diferenciação social.

Considerando tal evolução no nível de vida, a conseqüência é uma redução progressiva do tempo destinado às atividades alimentares domésticas, ou seja, o tempo dedicado ao 
abastecimento alimentar doméstico torna-se limitado. Cultivo de hortas, criações de animais de pequeno porte para consumo doméstico e outras atividades de subsistência são abandonadas. A otimização do tempo gasto durante as compras alimentares é obtida pela possibilidade destas serem realizadas em um mesmo local (desenvolvimento de grandes supermercados). A redução da freqüência de compras de alimentos é conseguida pelo surgimento e desenvolvimento de novas tecnologias de conservação de alimentos e, principalmente, pelo desenvolvimento da cadeia do frio (estoque de alimentos em congeladores e refrigeradores, permitindo o prolongamento da vida útil dos produtos). Preparações alimentares a partir de produtos brutos são progressivamente abandonadas. Consumidores declaram preferir produtos prontos para o consumo ou produtos que exijam pouca dedicação durante o seu preparo (produtos já cozidos ou pré-cozidos e produtos com embalagens que permitam serem colocados diretamente no forno ou microondas). Pizzas, tortas prontas, saladas com molhos, sanduíches e algumas sobremesas elaboradas podem ser citados como exemplos desses produtos (Figura 9).

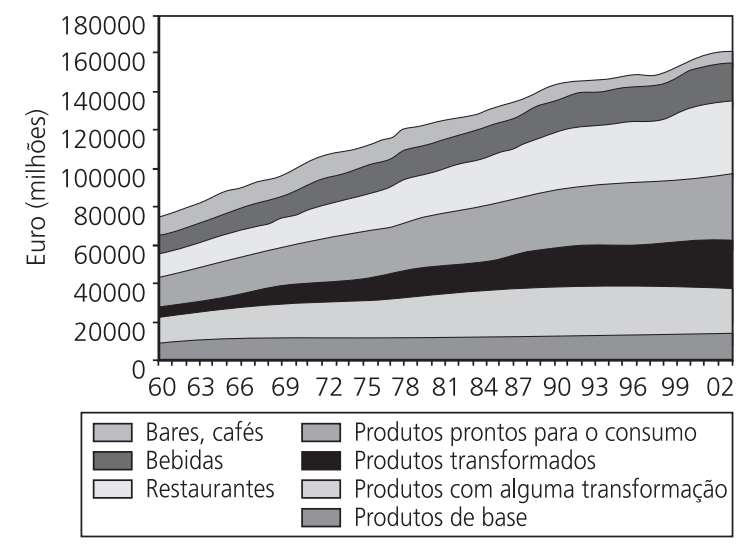

Figura 9. Escolha alimentar francesa, segundo renda do domicílio, quanto ao nível de transformação dos produtos consumidos e o local de consumo.

Fonte: INSEE ${ }^{15}$, citado por LAMBERT ${ }^{15}$.
Dessa forma, conclui-se que o desenvolvimento econômico e evoluções associadas aos modos de vida proporcionam uma transferência da produção doméstica alimentar para a aquisição dos alimentos via mercado. Tal afirmação é verificada pela diminuição do consumo de subsistência, aumento da demanda por produtos prontos para o consumo e crescimento do número de consumidores que afirmam realizar suas refeições em restaurantes ${ }^{8}$.

\section{As evoluções das formas e números de contatos alimentares ocorridos durante um dia}

Quando os indivíduos são questionados sobre os alimentos que foram consumidos no dia anterior, obtém-se uma resposta que, geralmente, corresponde aos alimentos consumidos nas últimas refeições. Assim, cabe ressaltar que, principalmente em países latinos, a análise das respostas obtidas por tais questionamentos contribui para o entendimento de normas sociais dominantes nessas sociedades e que impõem regras sobre o consumo alimentar de um povo ${ }^{18}$.

Entretanto, deve-se destacar que, durante um dia inteiro, as pessoas realizam, além das refeições habituais (café da manhã, almoço e jantar), outros contatos com alimentos que acabam sendo desconsiderados pelos mesmos por não representarem verdadeiras refeições. Esses contatos - alimentares realizados além das refeições oficiais - podem ser efetuados segundo influência de alguns fatores que merecem ser investigados e destacados. Com isso, deve-se considerar:

- sua organização no tempo: duração, freqüência, regularidade e valor (refeições festivas ou ordinárias);

- sua organização no espaço: local (no domicílio ou fora do domicílio) e utensílios domésticos utilizados (utilização de garfo e faca, palitos, mãos); 
- seu grau de comensalidade: refeição convivial (número de convidados, grau de parentesco), tipo de serviço adotado (self service ou serviço realizado por terceiros), tipo de ambiente e grau de intimidade durante a realização da refeição (jantar formal ou churrasco informal de final de semana, por exemplo);

- seu conteúdo: repertório de pratos (alimentos sólidos e líquidos), quantidades de pratos e tipo de culinária;

- grau de normalização: estrutura da refeição (prato único ou entrada, prato principal e sobremesa), nomes das refeições (café da manhã, almoço e jantar), rituais praticados e regras de comportamento durante as práticas alimentares.

Desta forma, pode-se afirmar que os tipos de contatos alimentares variarão segundo seus contextos (local, momento, grau de convivialidade). A Figura 10 mostra uma esquematização dos tipos de contatos alimentares praticados atualmente na França. A organização no tempo e conteúdos das refeições (líquidos e sólidos, salgados e doces, bem como quantidades ingeridas), encontram-se no eixo vertical. A organização, o espaço e o grau de comensalidade são representados no eixo horizontal. O aumento do grau de normalização dos contados alimentares é verificado da esquerda para a direita.

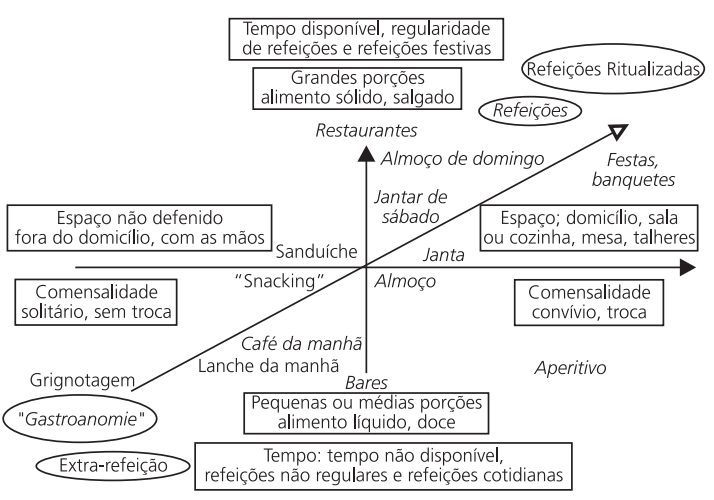

Figura 10. Os tipos de contatos alimentares atuais dos franceses.

Fonte: Lambert ${ }^{15}$
A maior parte dos contatos alimentares, apresentados na Figura 10, são chamados de refeições. Entretanto, conforme afirmado anteriormente, existem outros tipos contatos alimentares menos institucionalizados ou normalizados. Fischler ${ }^{17}$ considera que a característica individualista dos indivíduos e a evolução dos modos de vida contribuem para a diminuição da ritualização dos contatos alimentares. Essa tendência à redução da influência de normas alimentares atuando sobre os comportamentos é chamada pelo autor de gastro-anomia. O declínio de influências religiosas e morais sobre ações de povos de sociedades ricas ocidentais também contribui para uma maior liberdade dos mesmos na realização de práticas alimentares menos ritualizadas.

Considerando o novo contexto de superabundância alimentar, a convivialidade associada às refeições (consumo dos mesmos alimentos em uma refeição, como por exemplo, um prato principal para a família), vem perdendo importância. A falta de tempo e o consumo de pratos diferentes pelos membros da família é uma situação cada vez mais comum em grandes cidades. De modo geral, na França, foi constatado que $80 \%$ das pessoas realizam as refeições almoço e jantar com familiares ou entre amigos, porém essa afirmação não implica em consumo do mesmo prato. Quanto ao café da manhã e outros contatos alimentares menos ritualizados, esses são praticados de forma solitária.

Ainda considerando o caso francês, mesmo que o modelo de três ou quatro refeições diárias ainda seja citado como norma, numerosos fatores contribuem para o desenvolvimento e popularização de novas formas de contatos alimentares mais simples e individualizados. Mudanças demográficas (como o envelhecimento da população e a redução do tamanho das famílias), bem como a modificação dos sistemas de valores dos indivíduos (como o aumento do individualismo e redução da importância de contatos sociais) são exemplos desses fatores que reforçam a tendência da realização de refeições mais individualizadas. 
A falta de regularidade das refeições e seu caráter individual são, também, decorrência da mudança no ritmo de vida dos indivíduos. Entre outros fatores, tal mudança pode ser justificada pela organização do trabalho em horário flexível (manhã, tarde ou noite), realização de grandes deslocamentos e distância entre local de trabalho e a residência. Cabe, ainda, destacar que a grande oferta de alimentos e o desenvolvimento de produtos prontos para serem consumidos, ou que não exijam muita dedicação no preparo, além de sistemas de entrega em domicilio e restaurantes rápidos, também favorecem a realização de refeições individualizadas e rápidas (Figura 11).

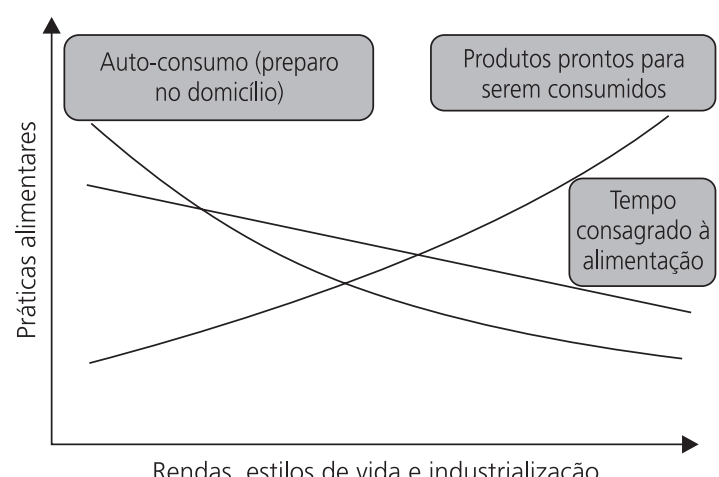

Figura 11. Evolução das práticas alimentares e do tempo Fonte: Lambert ${ }^{15}$. consagrado à alimentação.

\section{Modificações na oferta de alimentos}

Em mercados que chegaram em um estágio de maturidade, as indústrias alimentares que desejam ampliar o conjunto dos negócios realizados vêm investindo em estratégias de diferenciação com foco em inovação. A fase de maturidade e declínio desses mercados deve-se, sobretudo, à falta de investimento na composição dos produtos, pouca inovação dos mesmos e falta de modificação nas embalagens. O desenvolvimento dos estudos sobre os componentes nutricionais dos alimentos aplicados nas áreas de conservação (como secagem, defumação, salga, esterilização e congelamento) e a transformação dos mesmos (a partir de estudos da engenharia genética, por exemplo, os produtos geneticamente modificados) vêm permitindo a essas indústrias o oferecimento de novos produtos no mercado.

Até a metade do século XX o universo alimentar dos indivíduos (quanto a variedades de alimentos) era relativamente estável ao longo de suas vidas. Considerando-se tal universo, para o caso de populações atuais (século XXI), percebe-se uma grande evolução em relação às opções de alimentos oferecidas em períodos diferentes de suas vidas. Entretanto Lambert ${ }^{9,19}$ afirma que, embora os indivíduos estejam habituados com ocorrências de evoluções constantes, considerando diferentes domínios, nota-se que as representações alimentares dos mesmos evoluem mais lentamente do que os sistemas de produção-distribuição ligados à alimentação.

Em um sistema internacional e complexo de produção e distribuição alimentar, os indivíduos, enquanto consumidores finais, têm informações genéricas sobre os locais de venda dos alimentos e sobre os próprios produtos. Assim, todo o processo de produção por que passam os alimentos até chegarem nos pontos de venda é completamente desconhecido por aqueles que os consomem. Além disso, os profissionais da cadeia agroalimentar não têm se preocupado em informar os consumidores finais acerca das evoluções desse sistema. Tal desconhecimento gerou, nos últimos dez anos, sobretudo em consumidores de países industrializados, uma grande ansiedade em relação aos alimentos consumidos.

A distância entre os diferentes agentes que participam da cadeia produtiva em questão e os consumidores aumentou significativamente, ao longo da segunda metade do século 20. Entre os principais motivos que provocaram tal distância estão a urbanização, a divisão mais complexa de tarefas entre os agentes da cadeia e a globalização crescente do sistema de produção e distribuição alimentar. Tal afastamento e falta de informação contribuíram para que os consumidores manti- 
vessem a mesma imagem agrícola e artesanal que a produção rural tinha até os anos sessenta do século XX. Assim, quando eventos como o surgimento da encefalopatia espongiforme bovina (doença da vaca louca) são anunciados aos consumidores, esses passam a se questionar sobre o desconhecimento do sistema de produção dos alimentos e uma maior ansiedade emerge. A busca por informações, muitas vezes, acaba aumentando a insegurança e provocando medo nos indivíduos. Descobertas recentes de condutas de criação animal desaprovadas pelos consumidores, podem ser um exemplo desse novo processo de desconfiança e medo vividos pelos indivíduos.

O sistema de alta produtividade desenvolvido após os anos de penúria alimentar, que visou assegurar uma autonomia nacional de abastecimento alimentar, não parece corresponder a uma situação de abundância alimentar vivida por países ricos na organização mundial do comércio.

\section{O paradoxo da segurança sanitária dos alimentos}

O aumento da esperança de vida das populações e vários outros fatores, tais como a diminuição de ação de influências religiosas sobre os mesmos, podem estar fazendo com que os indivíduos não aceitem a morte de forma tácita. Além disso, evoluções dos conhecimentos científicos levam os indivíduos a acreditarem que, para a ciência, tudo pode ser possível. Em relação aos alimentos, entre outras constatações, tais conhecimentos permitiram a detecção de novos elementos patogênicos e o desenvolvimento de novas técnicas de controle que limitam casos de infecções e riscos alimentares. Entretanto, observa-se que são os riscos raros, ou eventuais problemas ligados à alimentação, que despertam no consumidor a ansiedade já mencionada por este trabalho.

Nesse contexto de ansiedade alimentar, quando os consumidores desconhecem os efeitos que poderiam ser causados pelo consumo de novos produtos, esses tendem a sobressaltar possíveis efeitos negativos. Riscos do surgimento de doenças provocadas por excessos de hormônio contidos nos alimentos, casos de doenças como a encefaloptia espongiforme bovina e incertezas quanto ao consumo de produtos geneticamente modificados (OGM), são exemplos de efeitos negativos dos alimentos que causam ansiedade nos consumidores. Nesses casos, o sistema límbico dos indivíduos os faz priorizar a rejeição de produtos que lhes pareçam nocivos, evitando, dessa forma, possíveis avaliações mais racionais sobre efeitos positivos e negativos desses alimentos. Nesse caso, a atitude dos indivíduos é considerada como binária, pois implicará no consumo ou rejeição de um produto. Existem casos de consumidores mais ousados e dispostos a experimentar alimentos desconhecidos, porém face a novos produtos com composição nutricional considerada ameaçadora, segundo definição dos próprios consumidores, a maior parte dos indivíduos adota um comportamento cauteloso.

Em sociedades que vivem situações de abundância alimentar, o campo das possibilidades de escolhas alimentares é maior. Porém, quando os consumidores acreditam que essa liberdade está ameaçada, por exemplo, quando indústrias declaram utilizar OGM para produzir seus produtos finais, é comum que ocorram fortes reações por parte dos consumidores. Nesse caso, os discursos de cientistas têm pouco efeito junto aos mesmos.

\section{Consumidores e cidadãos}

Em sociedades democráticas, os cidadãos não aceitam as imposições e buscam constantemente o debate e discussão de possibilidades. Estes reivindicam, sobretudo, a deferência quanto à sua integridade física (a saúde) e identidade, sendo particularmente sensíveis no que diz respeito à sua alimentação. Os cidadãos, enquanto consumidores, reprovam atitudes passivas e defendem posições ativas buscando não serem enganados. Segundo essa nova realidade, o Centro de Pesquisas para Estudo e Observação de 
Condições de Vida Francês (CREDOC), os define como sendo - "consumatores".

Essa mudança observada na atitude dos consumidores deve-se, em parte, a uma alteração de poder entre os diferentes agentes da cadeia produtiva. Como discutido anteriormente, observase que as cadeias mais tradicionais e especializadas, coordenadas pelos agricultores, transformaram-se progressivamente em fornecedores de matéria-prima e de produtos semielaborados para indústrias que atuam em cadeias produtivas alimentares complexas e cada vez mais globalizadas. Tais cadeias têm sido, cada vez mais, coordenadas pelos agentes do elo distribuição, os quais são fortemente influenciados por opiniões de consumidores mais conscientes e exigentes. Indivíduos vêm reivindicando o direito pela informação sobre os produtos (suas composições), sobre os sistemas de produção (informações sobre origem do produto e modos de preparo) e sobre as conseqüências futuras que o consumo desses produtos poderá lhes causar. Assim, caso os sistemas de produção e as escolhas tecnológicas adotadas para produção dos alimentos não thes pareçam convenientes, segundo seus sistemas de valores (produtos geneticamente modificados e utilização de farinhas animais como alimento para animais que, normalmente, não consomem carne, por exemplo), discussões são promovidas pelos consumidores junto aos atores públicos e privados. Outra constatação é a ocorrência de reivindicações pelo respeito ao meio-ambiente (entre outras, poluição do ar e água, preservação da natureza, bem estar dos animais). As crescentes demandas por produtos da agricultura orgânica correspondem a tais preocupações. O desenvolvimento do comércio solidário e a luta contra o trabalho infantil também podem ser apontados como exemplos de comportamentos éticos que insistem sobre a questão do respeito aos demais cidadãos.

\section{A globalização das gastronomias}

O aumento das trocas de informações sobre práticas alimentares, passando de um nível local para mundial, causa confrontações culturais entre grupos sociais. Tais trocas se efetuam segundo o processo sociológico de imitação e distinção. Os grupos sociais dominados (pobres, rurais, países em desenvolvimento) imitam os grupos sociais dominantes (ricos urbanos ocidentais). Classes abastadas ocidentais se tornam modelo para as populações ricas de países em desenvolvimento, como o Brasil. Com isso, observam-se representações, atitudes e comportamentos alimentares de brasileiros muito próximas àquelas dominantes na França. Grandes tendências de evoluções de comportamentos alimentares, principalmente de países ricos ocidentais, têm uma probabilidade muito forte de serem praticadas ao longo dos próximos anos em países em desenvolvimento, como o Brasil. Os resultados de uma ampla pesquisa, que procurou investigar a ação de diferentes determinantes (sociodemográficos, socioeconômicos e socioculturais) sobre práticas alimentares de consumidores brasileiros, confirmam tal afirmação. Tal pesquisa foi financiada pela Financiadora de Estudos e Projetos do Ministério da Ciência e Tecnologia (FINEP-MCT), realizada em 2003, e insere-se no âmbito de um acordo da Coordenação de Aperfeiçoamento de Pessoal de Nível Superior e Comitê Francês de Avaliação da Cooperação Universitária com o Brasil (CAPES-COFECUB) entre a Universidade Federal de São Carlos, a Universidade Federal de Mato Grosso do Sul e, pelo lado francês, a École Nationale d'Ingénieurs des Techniques des Industries Agricoles et Alimentaires (ENITIAA). Maiores detalhes referentes a tais resultados podem ser encontrados em Batalha et al. ${ }^{20}$.

Buscando uma distinção do resto da população, os ricos ocidentais preferem o exotismo como sinal de ostentação. O resultado dessa opção é a adaptação de diferentes gastronomias aos hábitos dos consumidores que as importam, dando origem a criações e adaptações culinárias. A globalização de trocas econômicas aumenta as variedades de tipos de alimentos disponíveis. Associada à globalização das trocas culturais, temse uma evolução de culturas alimentares (preferências e comportamentos). 
Porém, como a alimentação é um importante fator de identidade, as trocas gastronômicas implicam na ocorrência de dúvidas sobre a identidade dos indivíduos. Com isso, pode-se perceber a ocorrência de rejeições em relação a determinados símbolos de outras culturas. Um exemplo seria a rejeição dos franceses ao modelo alimentar americano. Essa rejeição é reforçada pelos europeus no sentido de defender o modelo alimentar francês e promover os produtos típicos de cada região. Por fim, conclui-se que a segurança alimentar dos pobres não é uma nova preocupação dos ricos. Campanhas que reforçam ações de caridade, campanhas contra a fome, auxílio à alimentação, entre outras, são encontradas em várias sociedades.

Porém, considerando a nova situação geopolítica das relações norte-sul, poder-se-ia propor a seguinte questão: a segurança alimentar dos pobres não se tornará a segurança dos ricos?

\section{REFERÊ N CIAS}

1. Flandrin JL, Montanari M. Histoire de I'alimentation. Paris: Fayard; 1996.

2. McIntosh WA. Sociologies of food and nutrition. Edition Plenium Press; 1996.

3. Kempf $\mathrm{H}$. Alerte pour 800 millions d'hommes sous-alimentés. Le Monde. 2002; (23 août):2.

4. Fischler $C$. Le paradoxe de l'abondance. Manger, une Pratique Culturelle, Sciences Humaines. 2003; (135):22-6.

5. Lambert JL. Réflexions sur les évolutions économiques et sociales des systèmes alimentaires. Journée Professionnelle IAA-IDF. 7 décembre. Paris; 2004a.

6. Malassis L, Padilla M. Typologie mondiale des modèles de consommation alimentaire, Montpellier: ENSA-INRA-IAM; 1982.

7. Blandford D. Changes in food consumption patterns in the OECD area. Eur Rev Agric Econom. $1984 ; 11$.
8. Lambert JL. L'évolution des modèles de consommation alimentaire en France. Paris: Lavoisier Tec\&Doc; 1987.

9. Lambert JL. Evolution des habitudes alimentaires et conséquences sur les stratégies industrielles. In: La conservation des aliments, 9èmes rencontres scientifiques et techniques, Agoral. Nancy: Lavoisier; 1997. p.49-61.

10. Potherat $C$. La consommation française de produits carnés et de poissons au cours des trente dernières années. Thèse, INA Paris-Grignon; 1997.

11. Food Agriculture Organization [homepage on the Internet]. Summary of food and agriculture statistics 2003. Available from: http://www.fao.org

12. Rabobank International. Les marchés mondiaux des céréales. Céréales et dynamique de la demande alimentaire mondiale. Défiblé, Paris, 15 octobre; 1998.

13. PNNS. La santé vient en mangeant. Le guide alimentaire pour tous. Paris: INPES; 2002.

14. INSEE Résultats. La consommation des ménages en 2003, n 32 soc, juillet; 2004.

15. Lambert JL. Modes de vie et comportements alimentaires dans notre société actuelle. Colloque de l'institut français pour la nutrition des aliments et des hommes: entre science et idéologie, définir ses propres repères. Paris, 8 et 9 décembre; 2004b.

16. Vialles N. Le sang et la chair. Paris: Maison des Sciences de l'Homme; 1987.

17. Fischler C. L'homnivore. Paris: Odile Jacob; 1990.

18. Poulain JP. Manger aujourd'hui. Toulouse: Privat; 2001.

19. Lambert JL. Les mangeurs entre traditions et nouveautés: quelques spécificités du "marketing alimentaire". In: Giachetti I. Identités des mangeurs, images des aliments. Paris: Polytechnica; 1996; p.151-73.

20. Batalha MO, Lucchese T, Lambert JL. Hábitos de consumo alimentar no Brasil: realidade e perspectivas. In: Batalha MO. Gestão do agronegócio: textos selecionados. São Carlos: Edufscar; 2004. Capítulo 2.

Recebido para publicação em 1 de setembro de 2005 